\title{
Mapping Nighttime and All-Day Radiative Cooling Potential in Europe and the Influence of Solar Reflectivity
}

\author{
Roger Vilà (D, Marc Medrano and Albert Castell *(D) \\ Sustainable Energy, Machinery and Buildings (SEMB) Research Group, INSPIRES Research Centre, Universitat de \\ Lleida, Pere de Cabrera s/n, 25001 Lleida, Spain; roger.vila@udl.cat (R.V.); marc.medrano@udl.cat (M.M.) \\ * Correspondence: albert.castell@udl.cat; Tel.: +34-973003570
}

Citation: Vilà, R.; Medrano, M.; Castell, A. Mapping Nighttime and All-Day Radiative Cooling Potential in Europe and the Influence of Solar Reflectivity. Atmosphere 2021, 12, 1119. https://doi.org/10.3390/

atmos12091119

Academic Editors: Giulia Ulpiani, Chi Yan Tso and Yu-Bin Chen

Received: 22 July 2021

Accepted: 20 August 2021

Published: 31 August 2021

Publisher's Note: MDPI stays neutral with regard to jurisdictional claims in published maps and institutional affiliations.

\begin{abstract}
Radiative cooling is a natural process to cool down surfaces through the rejection of thermal radiation using the outer space as a cold sink, taking advantage of the transparency of the atmospheric windows $(8-14 \mu \mathrm{m})$, which partially matches the infrared radiation band. With the development of new materials that have a high reflectivity of solar radiation, daytime radiative cooling can be achieved. This phenomenon depends on the optical properties of the surface and the local weather conditions. In this research, climatological data from 1791 weather stations were used to present detailed nighttime and all-day radiative cooling maps for the potential implementation of radiative cooling-based technologies. The paper offers a parametric study of the variation of the potential as a result of decreasing the solar reflectivity. The results show that southern Europe is the region with the highest potential while northern Europe holds more hours of available radiative cooling. After varying the solar reflectivity from 1 to 0.5 the average power reduces from 60.18 to $45.32 \mathrm{~W} / \mathrm{m}^{2}$, and energy from 527.10 to $264.87 \mathrm{kWh} / \mathrm{m}^{2} \cdot$ year. For solar reflectivity lower than 0.5 , all-day radiative coolers behave as nighttime radiative coolers, but power and energy values improve significantly for high values of solar reflectivity. Small variations of solar reflectivity have greater impacts on the potential at higher reflectivity values than at lower ones.
\end{abstract}

Keywords: radiative cooling; nighttime radiative cooling; daytime radiative cooling; all-day radiative cooling; cooling potential; potential maps; spatial interpolation; Kriging; Europe

\section{Introduction}

Radiative cooling ( $\mathrm{RC}$ ) is a natural cooling process already used in $400 \mathrm{BC}$ in ancient Iran for ice production [1]. In recent years it has experienced a new awakening. During the 1960s and 1970s the phenomenon began to be studied systematically [2,3]. However, it is in this last decade, driven by the needs for a change in the model of energy production and consumption, when technologies based on RC are positioned as promising solutions for the production of clean and green energies for space cooling purposes.

Radiative cooling is known to be the process by which a surface reduces its temperature through the emission of thermal radiation into the outer space. It benefits from the high transparency of the atmosphere in 8-14 $\mu \mathrm{m}$ wavelength range, named atmospheric window, which partially matches the peak of infrared radiation emitted by terrestrial bodies at ambient temperatures. This cooling process occurs when a net imbalance exists between the emitted and the absorbed heat; solar radiation, atmospheric radiation and parasitic losses (convection and conduction) also accounted for in this net balance. This technique allows for achieving temperatures below ambient [4].

The first selective surfaces (also called emitters), emitting in the 8-14 $\mu \mathrm{m}$ range, were designed to achieve RC during night time [2,5]. In 1975, Catalanotti et al. [3] obtained radiative cooling during daytime, but the performance was poor. Overcoming solar radiation was a great challenge. In 2014, Raman et al. [6] demonstrated a temperature drop $-4-5{ }^{\circ} \mathrm{C}$ - below ambient under direct sunlight in photonic radiative cooling, which 
combined layers of $\mathrm{SiO}_{2}$ and $\mathrm{HfO}_{2}$ on top of a silver surface. The recent development of new multilayer thin structures [6-8], porous polymers [9-11], nanoparticle materials [12], metamaterials [13-16] and photonic crystals [17-19], allows the manufacture of selective surfaces which emit only in the 8-14 $\mu \mathrm{m}$ range while reflecting the incoming solar radiation.

Several authors have conducted simulation studies in order to predict the potential of radiative cooling technologies. Vall et al. [20] modelled the behavior of a system that combined solar collection and radiative cooling in order to determine the potential coverage of cooling and DHW requirements in residential and commercial buildings under different climates. Feng et al. [21] conducted a daytime RC simulation and experimentation and evaluated the most significate variables and concluded that, in order to maximize RC, ultra-low parasitic heat gains and maximum suppression of solar irradiance in the emitter was required. Bijarniya et al. [22] studied the radiative cooling potential in various climate conditions in five cities in India, and evaluated the performance of different RC systems (ideal emitters, broadband emitters and selective emitters). Carlosena et al. [23] studied the potential of daytime radiative cooling for mitigating the effects of urban heat islands and performed simulations of different applications and locations for a total of 15 theoretical materials and 7 existing materials used in emitters.

Prediction of radiative cooling potential in different areas could become an aid to drive public policies on the usage of renewable energies. In 1992, Argiriou et al. [24] estimated the sky temperature depression and the night time performance of a RC flat plate in different countries in southern Europe, and concluded that southern Europe exhibited a promising potential for a high application of this technology. Chang et al. [25] and Li et al. [26] used geostatistical prediction tools to model and to obtain radiative cooling potential maps in China and USA, respectively.

In this research we applied interpolation tools to generate annual nighttime and allday radiative cooling potential maps in Europe. A comparison of results between emitters with different reflectivity in the solar range is also offered. We present twenty maps corresponding to seven maps of annual power, seven maps of annual energy production and six maps of percentage of RC hours over total annual hours.

\section{Methods}

The parametric study of the variation of the all-day radiative cooling potential in Europe as a function of the reflectivity in the solar range of the emitter material was conducted based on meteorological data measured in 1791 weather stations. Kriging was the interpolation technique used to obtain radiative cooling maps.

\subsection{Data Acquisition}

The climatological data used was available in the Meteornorm database. Meteonorm is a recognized software in the field of energy simulation of buildings and solar facilities. The downloaded data corresponded to a total of 1791 weather stations distributed in 46 European countries. The distribution of these stations is shown in Figure 1. The data is related to the last volume of measured data available in Metonorm for the year 2005. The resulting dataset included information on weather variables recorded hourly for 365 days of the year. Stored variables included ambient temperature, atmospheric IR radiation and global horizontal solar radiation, relative humidity, clearness index of the sky and atmospheric pressure. Ambient temperature, global horizontal solar radiation, relative humidity, clearness index or atmospheric pressure are data measured at the weather station while atmospheric radiation $\left(L_{i n}\right)$ is calculated based on the Aubinet model (1) [27]:

$$
L_{i n}=\sigma \cdot\left[94+12.6 \log \left(100 \cdot e_{s}\right)-13 \cdot K T_{d}+0.341 \cdot\left(T_{a}+273.15\right)\right]^{4}
$$

where $L_{\text {in }}$ is the atmospheric radiation $\left(\mathrm{W} / \mathrm{m}^{2}\right) ; \sigma$ is the Stefan-Boltzman constant $\left(\mathrm{W} \frac{\mathrm{m}^{2}}{\mathrm{~K}^{4}}\right)$; $e_{s}$ is the saturated vapor pressure (hPa); $K T_{d}$ is the clearness index (-) and $T_{a}$ is the ambient temperature $\left({ }^{\circ} \mathrm{C}\right)$. 


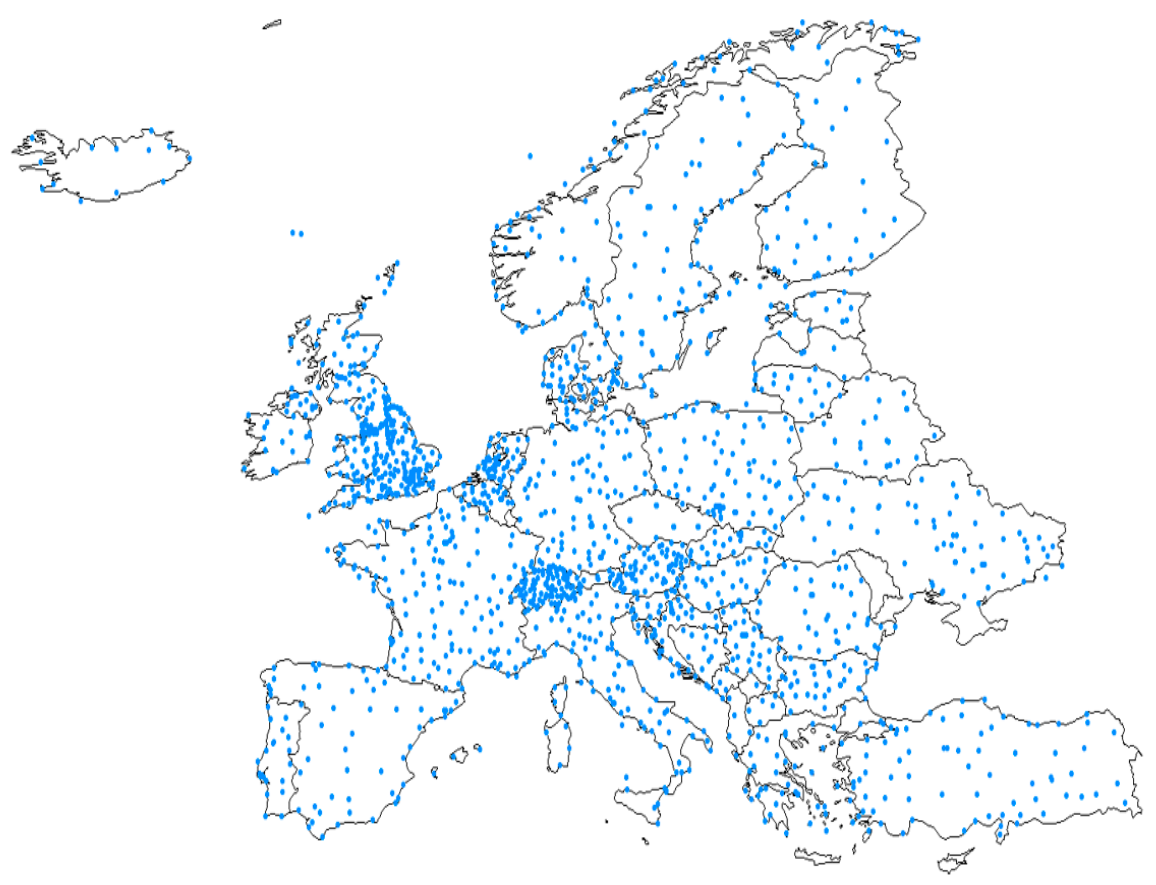

Figure 1. Spatial distribution of the sample points.

\subsection{Radiative Cooling Calculation}

In the research, the following premises were assumed: the greatest potential of a black-body surface (emittance of the surface $\left(\varepsilon_{s}\right)$ equal to one) (a) could be achieved by minimizing the parasitic losses of conduction and convection, (b) while absorbed solar radiation depended on the reflectivity of the surface. In this study, $\varepsilon_{s}$ is equal to 1 and parasitic losses are neglected. In RC applications, the emitter surface temperature is close to ambient temperature; in this case it was assumed that (c) the temperature on the surface was equal to ambient temperature. The net balance power per surface unit at each location was calculated (2).

$$
q_{\text {net, }, \text { ideal }}\left(T_{a}\right)=\sigma T_{a}^{4}-L_{\text {in }}-(1-\rho) S_{H}\left(\mathrm{~W} / \mathrm{m}^{2}\right)
$$

where $\rho$ is the solar reflectivity of the emitter (-) and $S_{H}$ corresponds to the global horizontal solar radiation $\left(\mathrm{W} / \mathrm{m}^{2}\right)$.

Only positive values of Equation (2), corresponding to observations where radiative cooling occurred, were filtered. The average annual RC potential at each location was calculated according to (3) where $n$ is the total number of positive observations:

$$
q_{r c, a v g}=\frac{\sum_{i}^{n} q_{n e t, i d e a l}{ }^{+}}{n}\left(\mathrm{~W} / \mathrm{m}^{2}\right)
$$

Every value from Equation (2) corresponded to a one-hour observation $(t=1 \mathrm{~h})$. Thus, allowing us to calculate the RC annual energy (6):

$$
e_{r c}=\frac{\sum_{i}^{n} q_{\text {net }, \text { ideal }}{ }^{+} \cdot t}{1000}\left(\frac{\mathrm{kWh}}{\mathrm{m}^{2}} \cdot \text { year }\right)
$$

Finally, a third value was included (5). This value referred to the number of observations where radiative cooling was achieved $\left(N\left[q_{\text {net, }}\right.\right.$ ideal $\left.\left.{ }^{+}\right]\right)$, compared to the total number of observations (8760).

$$
\text { coverage }=\frac{N\left(q_{\text {net }, \text { ideal }}{ }^{+}\right)}{8760}[\%]
$$




\subsection{Training and Test Datasets}

Data was divided into two subsets: training set and test set. The training set contained information from $80 \%$ of the locations and was used in the construction of the interpolation model for each value of $\rho$. Test set data was used to evaluate the performance of each model.

\subsection{Interpolation Kriging Model}

Kriging is a stochastic interpolation method for values prediction at different points from known reference values. In the study we used the most general version of the methodology, ordinary Kriging, which decomposed the regressor into a stationary part $(\mu)$ and a residual $\left(\varepsilon^{\prime}\right)$, corresponding to the spatially correlated part (6) [28]:

$$
Z(s)=\mu+\varepsilon^{\prime}(s)
$$

This method worked as a linear regression applied to spatial sample data which was used as regressor, $Z(s)$, in order to predict a dependent variable, $Z\left(s_{0}\right)$, at a given location (7). The weight given by the model to each of the points in the sample was determined by a variogram function (8).

$$
\begin{aligned}
& \hat{Z}\left(s_{0}\right)=\lambda_{0} Z(s) \\
& \left(\begin{array}{cccc}
\gamma\left(s_{1}-s_{1}\right) & \ldots & \gamma\left(s_{1}-s_{n}\right) & 1 \\
\vdots & \ddots & \vdots & 1 \\
\gamma\left(s_{n}-s_{1}\right) & \ldots & \gamma\left(s_{n}-s_{n}\right) & 1 \\
1 & \ldots & 1 & 0
\end{array}\right) \cdot \lambda_{0}=\left(\begin{array}{c}
\gamma\left(s_{1}-s_{0}\right) \\
\vdots \\
\gamma\left(s_{n}-s_{0}\right) \\
1
\end{array}\right)
\end{aligned}
$$

where $\lambda_{0}$ is a vector of Kriging weights, $n$ the number of sample points and $\gamma$ is the semivariance.

The semivariance of the sample was calculated for each pair of points from (9), where $Z\left(s_{i}\right)$ is the value of the target variable at the point $s_{i}, Z\left(s_{i}+h\right)$ is the value of the neighbor point at a distance $s_{i}+h$ and $E$ corresponds to the expected value. A theoretical variogram was adjusted to the variogram so that the error of the fitting was minimum.

$$
\gamma(h)=\frac{1}{2} E\left[\left(Z\left(s_{i}\right)-Z\left(s_{i}+h\right)\right)^{2}\right]
$$

\subsection{Assessment Metrics of the Model}

Radiative cooling values were predicted using the test set locations in the Kriging model. These predictions were compared with the existing potential values at these locations. In order to evaluate the accuracy of the model, the coefficient of determination $\left(R^{2}\right)$ and the root mean square error (RMSE) were calculated (10) and (11):

$$
\begin{gathered}
R^{2}=1-\frac{\sum_{i=1}^{N}\left(X_{i, m}-X_{i, p}\right)^{2}}{\sum_{i=1}^{N}\left(X_{i, m}-X_{m, a v g}\right)^{2}} \\
R M S E=\sqrt{\frac{1}{N} \sum_{i=1}^{N}\left(X_{i, m}-X_{i, p}\right)^{2}}
\end{gathered}
$$

where $N$ is the total number of locations; $X_{i, m}$ is the observed values of the sample; $X_{i, p}$ is the value estimated in the model and $X_{m, a v g}$ is the average of the observed values at the weather stations. RMSE has the same units as the variable at interpolation (power, energy and coverage) while $R^{2}$ is dimensionless.

\section{Results and Discussion}

In the first part of this section we present a comparison of the prediction maps for the cases of nighttime and all-day RC of an ideal reflective surface $(\rho=1)$. In the second part we determine the changes that occur when varying the value of surface reflectivity in all-day RC. In both sections the performance of the interpolation models used has been evaluated. 


\subsection{Nighttime and All-Day Comparison}

Figure 2 shows the annual potential maps of radiative cooling for night and ideal all-day cases. The maps were divided into three regions: south, center and north.

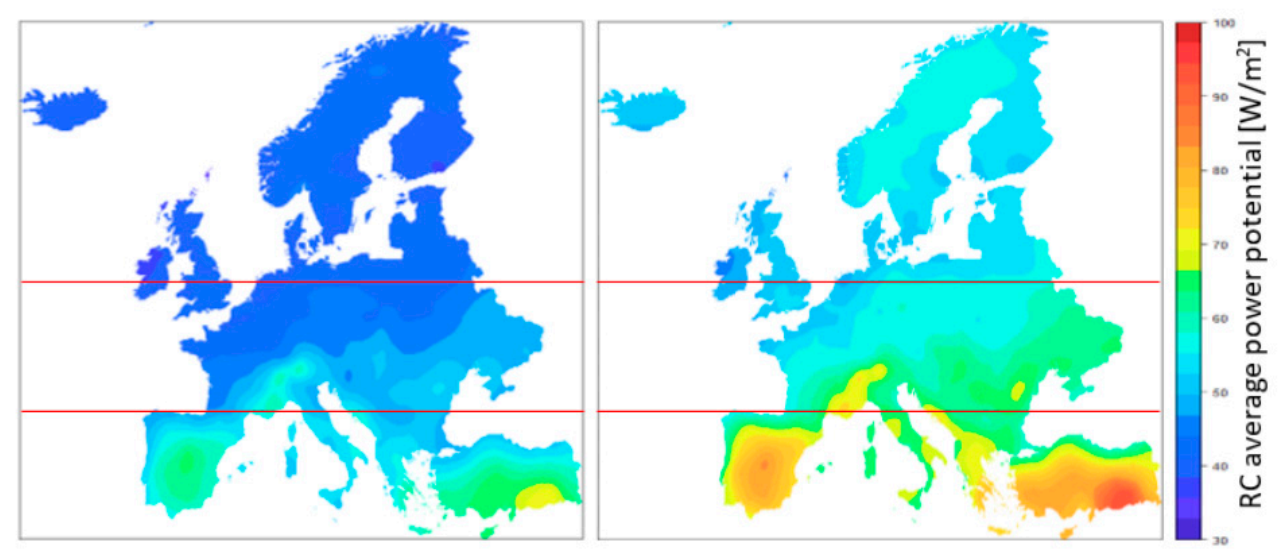

Figure 2. Map of annual average power potential $\left(\mathrm{W} / \mathrm{m}^{2}\right)$ of nighttime RC (left) and all-day RC of an ideal solar reflective surface (right). Horizontal red lines divide the map into three zones: north $(53.55 \mathrm{~N}-71.15 \mathrm{~N})$, center (43.46 N-53.55 N) and south (34.60 N-43.46 N).

In all-day applications, the potential RC was greater than in night applications. On average in Europe, the change to all-day applications represented an increase of $27.21 \%$ (from 47.30 to $60.17 \mathrm{~W} / \mathrm{m}^{2}$ ). The all-day map presented more diversification of the values with respect to the night map (in all-day the range is $43.82-94.01 \mathrm{~W} / \mathrm{m}^{2}$ and in nighttime, $35.14-71.34 \mathrm{~W} / \mathrm{m}^{2}$ ).

It was observed that the regions with the greatest potential were located in the south of Europe (57.36 W/ $/ \mathrm{m}^{2}$ in nighttime map and $72.33 \mathrm{~W} / \mathrm{m}^{2}$ in all-day), in the Mediterranean basin, especially the cases of Turkey, Spain and Greece. These results were consistent with the findings of Argiriou et al. [24]. The areas of least potential were in the northern countries $\left(41.51 \mathrm{~W} / \mathrm{m}^{2}\right.$ in nighttime map and $53.77 \mathrm{~W} / \mathrm{m}^{2}$ in all-day) where the temperature is lower. The average potential in the central zone was 46.48 (nocturnal) and 58.69 (all-day) and they are values comparable to those in the north but with a wider range of variability (Table 1). In these cases, the performance of the surface is only influenced by the temperature and the atmospheric radiation and the results are coherent with the climatology of Europe where the ambient temperature decreases with the latitude.

Table 1. Minimum, average and maximum annual average power potential of the different zones of Europe.

\begin{tabular}{|c|c|c|c|c|c|c|c|}
\hline & \multirow[b]{2}{*}{ Latitude Range } & \multicolumn{3}{|c|}{ RC Power (Nighttime) } & \multicolumn{3}{|c|}{ RC Power (All-Day) } \\
\hline & & $\min _{\left(\mathrm{W} / \mathrm{m}^{2}\right)}$ & $\underset{\left(\mathrm{W} / \mathrm{m}^{2}\right)}{\operatorname{avg}}$ & $\max _{\left(\mathrm{W} / \mathrm{m}^{2}\right)}$ & $\min _{\left(\mathrm{W} / \mathrm{m}^{2}\right)}$ & $\underset{\left(\mathrm{W} / \mathrm{m}^{2}\right)}{\operatorname{avg}}$ & $\max _{\left(\mathrm{W} / \mathrm{m}^{2}\right)}$ \\
\hline Center & $43.46 \mathrm{~N}-53.55 \mathrm{~N}$ & 37.95 & 46.48 & 60.11 & 46.43 & 58.69 & 73.08 \\
\hline North & $53.55 \mathrm{~N}-71.15 \mathrm{~N}$ & 35.14 & 41.51 & 45.31 & 43.82 & 53.77 & 57.81 \\
\hline South & $34.60 \mathrm{~N}-43.46 \mathrm{~N}$ & 46.67 & 57.36 & 71.34 & 56.36 & 72.33 & 94.01 \\
\hline Europe & $34.60 \mathrm{~N}-71.15 \mathrm{~N}$ & 35.14 & 47.30 & 71.34 & 43.82 & 60.17 & 94.01 \\
\hline
\end{tabular}

Annual energy potential maps are shown in Figure 3. The night map presented homogeneous values with minimal differences between regions. In the all-day predictions there was an average increase of $114 \%$ (124\% in the south, $116 \%$ in the center and $108 \%$ in the north) of the available annual energy potential: the average was $245.76 \mathrm{kWh} / \mathrm{m}^{2}$.year in the night case and $527.1 \mathrm{kWh} / \mathrm{m}^{2}$.year in the all-day case. This means that only during daytime can $281.34 \mathrm{kWh} / \mathrm{m}^{2}$.year be produced. In all-day applications, southern countries can radiate, on average, $633.56 \mathrm{kWh} / \mathrm{m}^{2}$.year; center countries, $514.16 \mathrm{kWh} / \mathrm{m}^{2} \cdot$ year; and 
northern countries, $470.99 \mathrm{kWh} / \mathrm{m}^{2}$.year (Table 2). On average, nighttime RC was achieved in $59.6 \%$ of the annual observations.

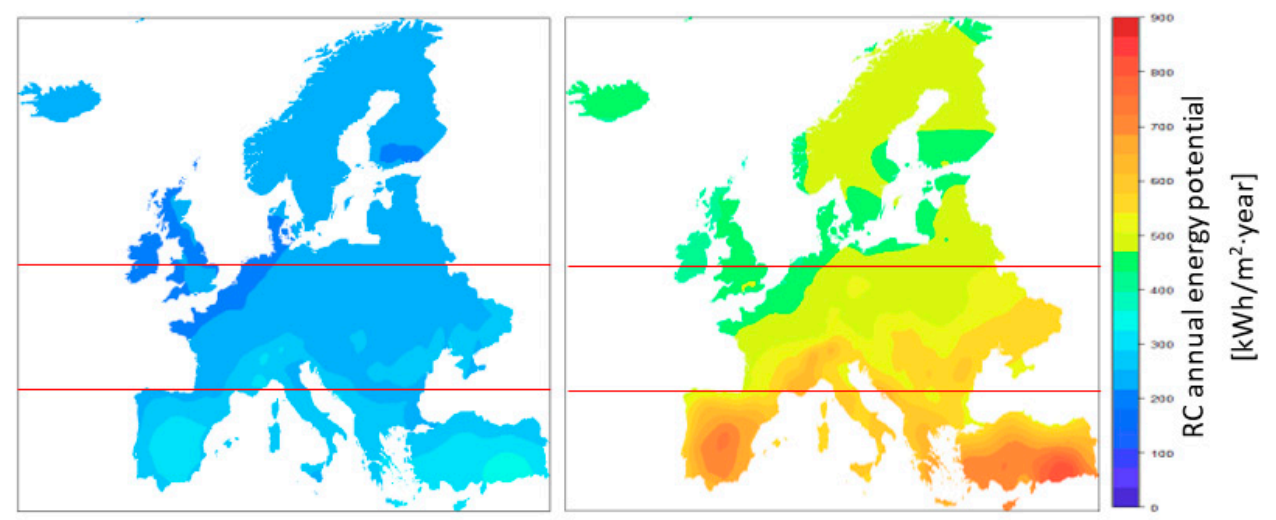

Figure 3. Map of annual energy potential $\left(\mathrm{kWh} / \mathrm{m}^{2}\right.$.year) of nighttime RC (left) and all-day RC of an ideal solar reflective surface (right). Horizontal red lines divide the map into three zones: north $(53.55 \mathrm{~N}-71.15 \mathrm{~N})$, center $(43.46 \mathrm{~N}-53.55 \mathrm{~N})$ and south $(34.60 \mathrm{~N}-43.46 \mathrm{~N})$.

Table 2. Minimum, average and maximum annual energy potential of the different zones of Europe.

\begin{tabular}{|c|c|c|c|c|c|c|c|}
\hline & \multirow[b]{2}{*}{ Latitude Range } & \multicolumn{3}{|c|}{ Energy (Nighttime) } & \multicolumn{3}{|c|}{ Energy (All-Day) } \\
\hline & & $\min _{\left(\mathrm{kWh} / \mathrm{m}^{2} \cdot \text { Year }\right)}$ & $\begin{array}{c}\text { avg } \\
\left(\mathrm{kWh} / \mathrm{m}^{2} \cdot \text { Year }\right)\end{array}$ & $\max _{\left(\mathrm{kWh} / \mathrm{m}^{2} \cdot \text { Year }\right)}$ & $\min _{\left(\mathrm{kWh} / \mathrm{m}^{2} \cdot \text { Year }\right)}$ & $\begin{array}{c}\text { avg } \\
\left(\mathrm{kWh} / \mathrm{m}^{2} \cdot \text { Year }\right)\end{array}$ & $\max _{\left(\mathrm{kWh} / \mathrm{m}^{2} \cdot \text { Year }\right)}$ \\
\hline Center & $43.46 \mathrm{~N}-53.55 \mathrm{~N}$ & 194.22 & 238.00 & 296.31 & 406.74 & 545.83 & 639.71 \\
\hline North & $53.55 \mathrm{~N}-71.15 \mathrm{~N}$ & 194.15 & 229.99 & 250.19 & 384.08 & 485.70 & 506.40 \\
\hline South & $34.60 \mathrm{~N}-43.46 \mathrm{~N}$ & 231.12 & 283.07 & 352.59 & 493.88 & 688.64 & 822.66 \\
\hline Europe & $34.60 \mathrm{~N}-71.15 \mathrm{~N}$ & 194.15 & 245.76 & 352.59 & 384.08 & 559.47 & 822.66 \\
\hline
\end{tabular}

Table 3 lists the values of the performances of the four models. In all cases, $R^{2}$ presented high values (between 0.83 and 0.91 ), which indicates that the models collected more than $83 \%$ of the variability of the sample data. In the energy models, the value of RMSE presented values of one order of magnitude greater, in agreement with the values of prediction.

Table 3. Performance of the nocturnal and all-day models.

\begin{tabular}{ccccc}
\hline & \multicolumn{2}{c}{ Power } & \multicolumn{2}{c}{ Energy } \\
\cline { 2 - 5 } & Nocturnal & All-Day & Nocturnal & All-Day \\
\hline \multirow{2}{*}{ RMSE } & 2.28 & 2.46 & 12.38 & 21.58 \\
$R^{2}$ & $\left(\mathrm{~W} / \mathrm{m}^{2}\right)$ & $\left(\mathrm{W} / \mathrm{m}^{2}\right)$ & $\left(\mathrm{kWh} / \mathrm{m}^{2} \cdot\right.$ year $)$ & $\left(\mathrm{kWh} / \mathrm{m}^{2} \cdot\right.$ year $)$ \\
\hline
\end{tabular}

\subsection{Influence of the Solar Reflectivity on the Performance of a Radiative Surface}

\subsubsection{Average Power Potential}

The annual RC power potential maps in Europe are displayed in Figure 4 for each value of reflectivity. The reduction of the reflectivity affects the three regions equally ( $25 \%$ reduction) but, in absolute values, the southern regions are especially penalized (average power reduced by $17.28 \mathrm{~W} / \mathrm{m}^{2}$ ). It is observed that the maps tend to homogenize results throughout the territory as the reflectivity is reduced: the range of values (minimum to maximum average power potential) diminished from 50.19 to $35.05 \mathrm{~W} / \mathrm{m}^{2}$. 

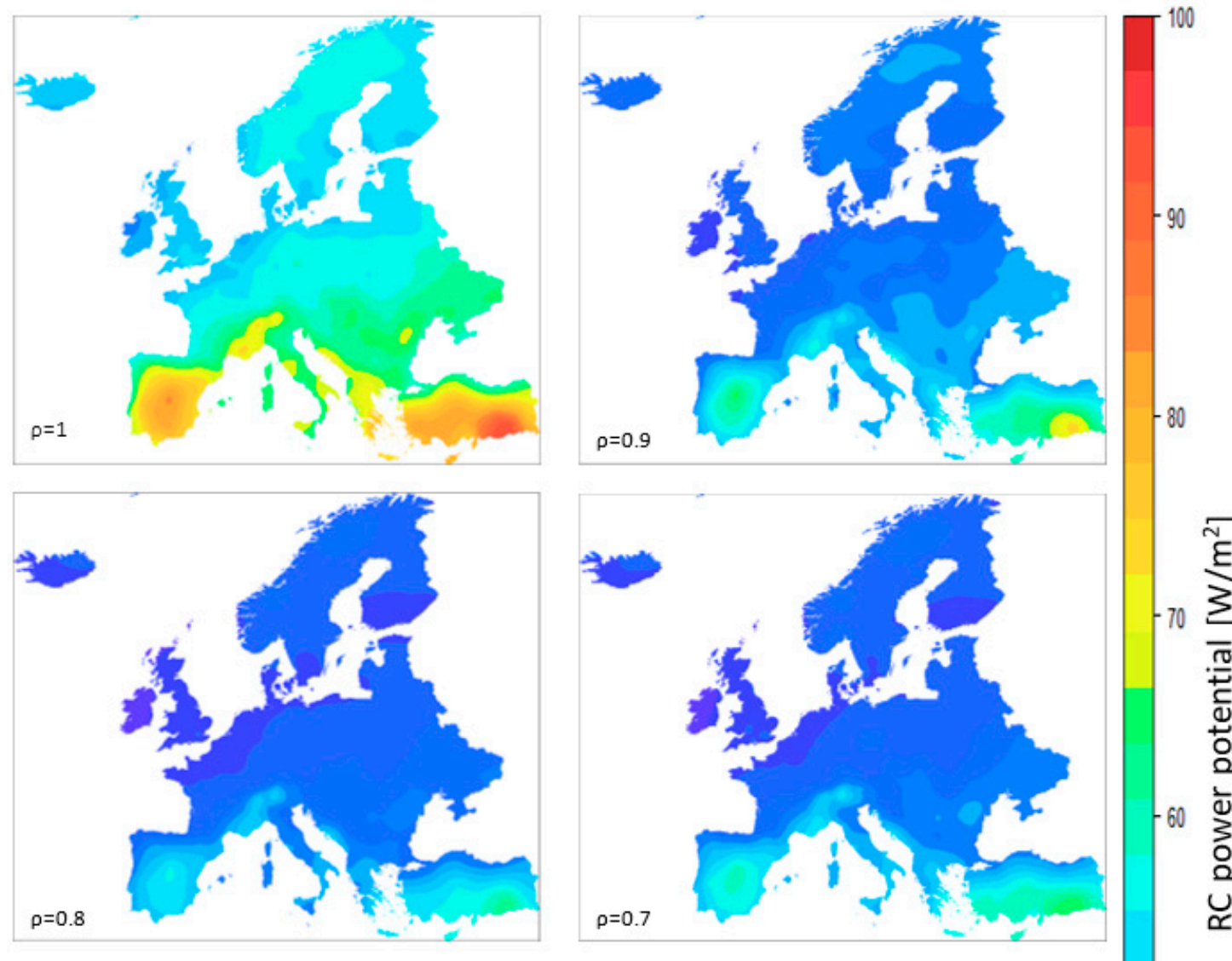

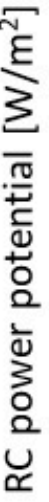
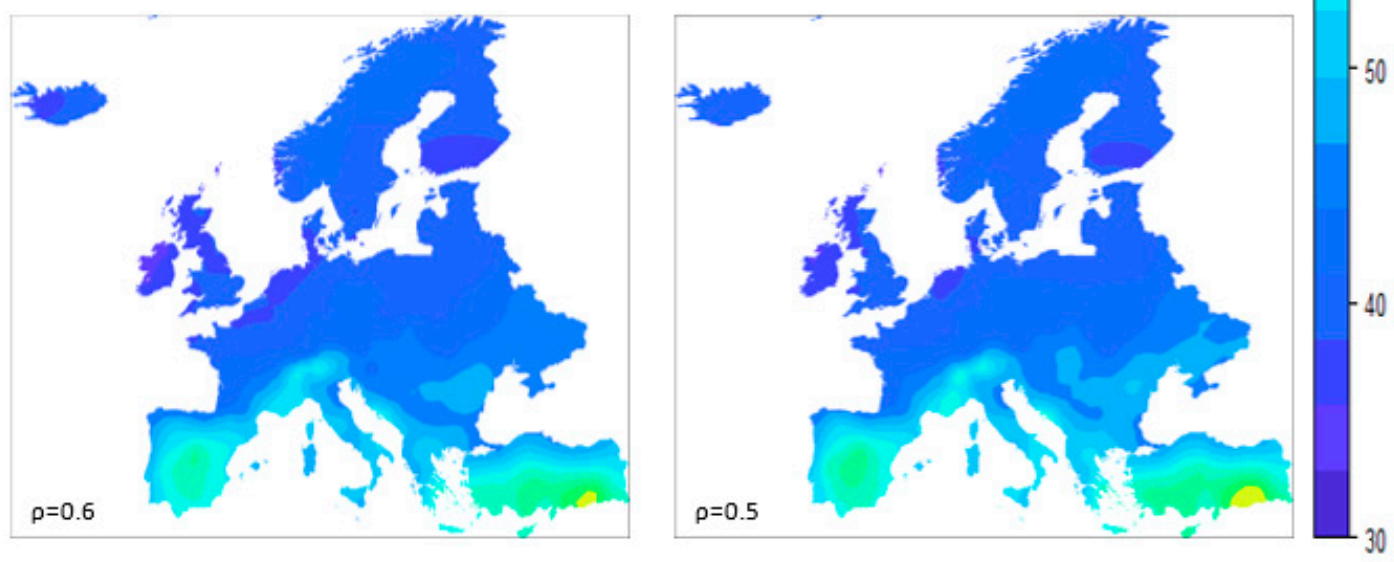

Figure 4. Map of RC power potential $\left(\mathrm{W} / \mathrm{m}^{2}\right)$ for six values of solar radiation reflectivity.

Table 4 shows that the average value of the potential of RC power followed a decreasing trend for solar reflectivity from 1 to 0.8 , while between 0.7 and 0.5 the potential increased slightly; 0.8 being the value of solar reflectivity where the average potential was minimum $\left(42.61 \mathrm{~W} / \mathrm{m}^{2}\right)$. Between 1 and 0.8 a maximum difference of potentials occurred: reducing the solar reflectivity from 1 to 0.8 caused a decrease of $29 \%$ in the potential of RC power. Between 0.8 and 0.5 , the potential increased $6.4 \%$.

The explanation behind these results is due to the number of observations with which the annual average is calculated. With the reduction of the reflectivity, the total number of RC observations also decreases (see Section 3.2.2). To better understand this, Figure 5 is displayed. The figure shows the power calculated in each of the observations for the month of February at the location of Batman. Observations that resulted in high power values when $\rho=1$ remained high when $\rho=0.5$, while those observations with low power decreased to the point of having negative values (red points) and were discarded in the 
calculation of the average. As a result, the calculation of the average for solar reflectivity 0.5 and 0.6 had few observations but of higher quality than for solar reflectivity 0.7 and 0.8 . This phenomenon is a result of the different heat fluxes occurring during nighttime and daytime RC. During nighttime RC, solar radiation is not present, thus solar reflectivity does not play any role. However, during daytime RC, solar reflectivity has a significant impact on the radiative balance. In Section 3.2.2. we discuss that most of the observations of RC when considering a solar reflectivity of 0.6 and 0.5 are during nighttime, and thus not affected by this parameter.

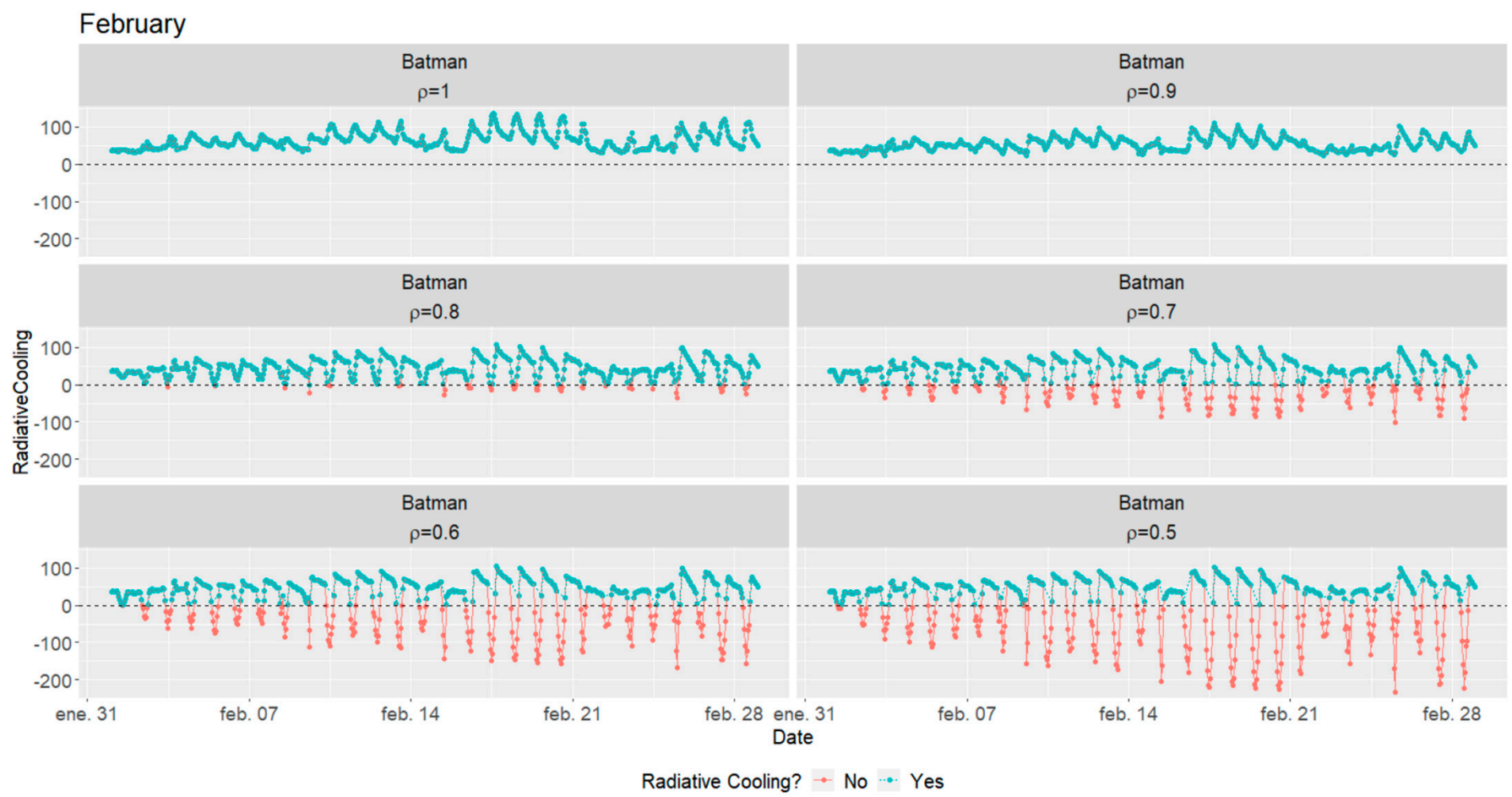

Figure 5. Power potential for each observation in Batman during the month of February and for each value of solar reflectivity. Blue points correspond to radiative cooling observations and red points correspond to solar heating observations. Red observations were discarded in calculations.

Table 4. Minimum, average and maximum values for each solar reflectivity. Potential maps of RC power $\left(\mathrm{W} / \mathrm{m}^{2}\right)$.

\begin{tabular}{|c|c|c|c|c|c|c|c|c|}
\hline & \multirow[b]{2}{*}{ Latitude Range } & & \multicolumn{6}{|c|}{ Solar Reflectivity } \\
\hline & & & 1 & 0.9 & 0.8 & 0.7 & 0.6 & 0.5 \\
\hline \multirow{3}{*}{ Center } & \multirow{3}{*}{$43.46 \mathrm{~N}-53.55 \mathrm{~N}$} & $\min$ & 46.43 & 36.31 & 34.20 & 34.65 & 35.09 & 35.82 \\
\hline & & avg & 58.69 & 45.27 & 41.31 & 42.40 & 43.34 & 44.12 \\
\hline & & $\max$ & 73.08 & 56.17 & 51.62 & 53.81 & 55.98 & 57.87 \\
\hline \multirow{3}{*}{ North } & \multirow{3}{*}{$53.55 \mathrm{~N}-71.15 \mathrm{~N}$} & $\min$ & 43.82 & 35.70 & 33.78 & 33.55 & 33.88 & 34.09 \\
\hline & & avg & 53.77 & 43.76 & 39.31 & 39.59 & 39.95 & 40.23 \\
\hline & & $\max$ & 57.81 & 48.00 & 42.19 & 42.25 & 42.90 & 43.38 \\
\hline \multirow{3}{*}{ South } & \multirow{3}{*}{$34.60 \mathrm{~N}-43.46 \mathrm{~N}$} & $\min$ & 56.36 & 42.23 & 40.80 & 42.43 & 43.67 & 44.41 \\
\hline & & avg & 72.33 & 54.33 & 49.84 & 52.51 & 53.72 & 55.05 \\
\hline & & $\max$ & 94.01 & 72.76 & 62.24 & 66.05 & 67.16 & 69.14 \\
\hline \multirow{3}{*}{ Europe } & \multirow{3}{*}{$34.60 \mathrm{~N}-71.15 \mathrm{~N}$} & $\min$ & 43.82 & 35.70 & 33.76 & 33.55 & 33.88 & 34.09 \\
\hline & & avg & 60.18 & 46.87 & 42.61 & 43.79 & 44.59 & 45.32 \\
\hline & & $\max$ & 94.01 & 72.56 & 62.34 & 66.05 & 67.16 & 69.14 \\
\hline
\end{tabular}

We did not observe significant differences in performance of the model for each reflectivity value (Table 5). In all six cases, the values of $R^{2}$ were greater than 0.80 which 
means that, in all the cases, the models could explain more than $80 \%$ of the variability of the sample values. RMSE values were small, indicating that the models had good accuracy.

Table 5. Performance of the model of the potential maps of power for different solar reflectivity values.

\begin{tabular}{ccc}
\hline Reflectivity & $\boldsymbol{R}^{\mathbf{2}}(-)$ & RMSE $\left(\mathbf{W} / \mathbf{m}^{\mathbf{2}}\right)$ \\
\hline 1 & 0.91 & 2.46 \\
0.9 & 0.84 & 2.40 \\
0.8 & 0.87 & 1.90 \\
0.7 & 0.87 & 2.16 \\
0.6 & 0.90 & 2.02 \\
0.5 & 0.88 & 2.32 \\
\hline
\end{tabular}

\subsubsection{RC Activity}

The maps in Figure 6 show the percentage of hours in a year that the emitter was able to achieve radiative cooling (from now on we refer to this observation of net radiative cooling as "RC activity"). When the reflectivity in the solar range is reduced, the material decreases its behavior as a selective material: when it absorbed more solar radiation the number of observations in which the surface was unable to do radiative cooling increased. In these daytime observations the device was actually behaving as a solar thermal collector, heating up the surface.

Contrary to what the power maps showed, the percentage of RC activity of the emitter decreased as reflectivity decreased in the six cases (Table 6). For a reflectivity of 0.5 , the worst-case scenario, only in $67 \%$ of cases was radiative cooling achieved; the remaining $33 \%$ were solar collection observations. Northern regions had more observations of radiative cooling, in all the cases, which means more time available to perform radiative cooling, than southern regions. In Section 3.1 it was pointed out that nighttime RC represented $59.6 \%$ of the RC activity in Europe, this means that only $7.47 \%$ of the activity occurred during daytime when $\rho=0.5 ; 10.81 \%$, when $\rho=0.6 ; 16.18 \%$, when $\rho=0.7 ; 26.98 \%$, when $\rho=0.8 ; 40.29 \%$, when $\rho=0.9$ and $40.4 \%$, when $\rho=1$.

The results of RC activity for $\rho=1$ have not been interpolated by Kriging as a variability in the values to be interpolated is required. For this case, all values were equal to $100 \%$ and Kriging could not be performed. It was assumed that in unknown locations the RC activity value was $100 \%$.

The model for reflectivity 0.9 showed a low $R^{2}$ value and low RMSE. This model could not reproduce much of the variability of the sample but it also gives low errors of prediction. The range of the values of the sample was very small. For reflectivity values below 0.9 , the models presented good metrics of $R^{2}$ and RMSE (Table 7).

Table 6. Minimum, average and maximum values for each solar reflectivity. RC Activity (\%).

\begin{tabular}{|c|c|c|c|c|c|c|c|c|}
\hline & \multirow[b]{2}{*}{ Latitude Range } & & \multicolumn{6}{|c|}{ Solar Reflectivity } \\
\hline & & & 1 & 0.9 & 0.8 & 0.7 & 0.6 & 0.5 \\
\hline \multirow{3}{*}{ Center } & \multirow{3}{*}{$43.46 \mathrm{~N}-53.55 \mathrm{~N}$} & $\min$ & 100 & 100 & 79.04 & 68.52 & 63.76 & 61.29 \\
\hline & & avg & 100 & 99.89 & 85.68 & 74.93 & 69.42 & 65.93 \\
\hline & & $\max$ & 100 & 98.55 & 89.41 & 78.36 & 73.07 & 69.55 \\
\hline \multirow{3}{*}{ North } & \multirow{3}{*}{$53.55 \mathrm{~N}-71.15 \mathrm{~N}$} & $\min$ & 100 & 99.72 & 84.34 & 76.60 & 70.87 & 67.07 \\
\hline & & avg & 100 & 99.96 & 90.42 & 80.53 & 75.21 & 71.66 \\
\hline & & $\max$ & 100 & 99.99 & 94.48 & 84.12 & 78.33 & 74.53 \\
\hline \multirow{3}{*}{ South } & \multirow{3}{*}{$34.60 \mathrm{~N}-43.46 \mathrm{~N}$} & $\min$ & 100 & 99.03 & 72.35 & 64.03 & 60.55 & 58.43 \\
\hline & & avg & 100 & 99.78 & 82.50 & 70.25 & 65.08 & 62.07 \\
\hline & & $\max$ & 100 & 99.96 & 90.32 & 73.37 & 67.73 & 64.50 \\
\hline \multirow{3}{*}{ Europe } & \multirow{3}{*}{$34.60 \mathrm{~N}-71.15 \mathrm{~N}$} & $\min$ & 100 & 98.55 & 72.35 & 64.03 & 60.55 & 58.43 \\
\hline & & avg & 100 & 99.89 & 86.58 & 75.78 & 70.41 & 67.07 \\
\hline & & $\max$ & 100 & 100 & 94.48 & 84.12 & 78.33 & 74.53 \\
\hline
\end{tabular}


Table 7. Performance of the model of the potential maps of RC activity for different solar reflectivity values.

\begin{tabular}{ccc}
\hline Reflectivity & $\boldsymbol{R}^{\mathbf{2}}(-)$ & RMSE (-) \\
\hline 0.9 & 0.25 & 0.19 \\
0.8 & 0.84 & 1.49 \\
0.7 & 0.87 & 1.43 \\
0.6 & 0.88 & 1.24 \\
0.5 & 0.91 & 1.05 \\
\hline
\end{tabular}
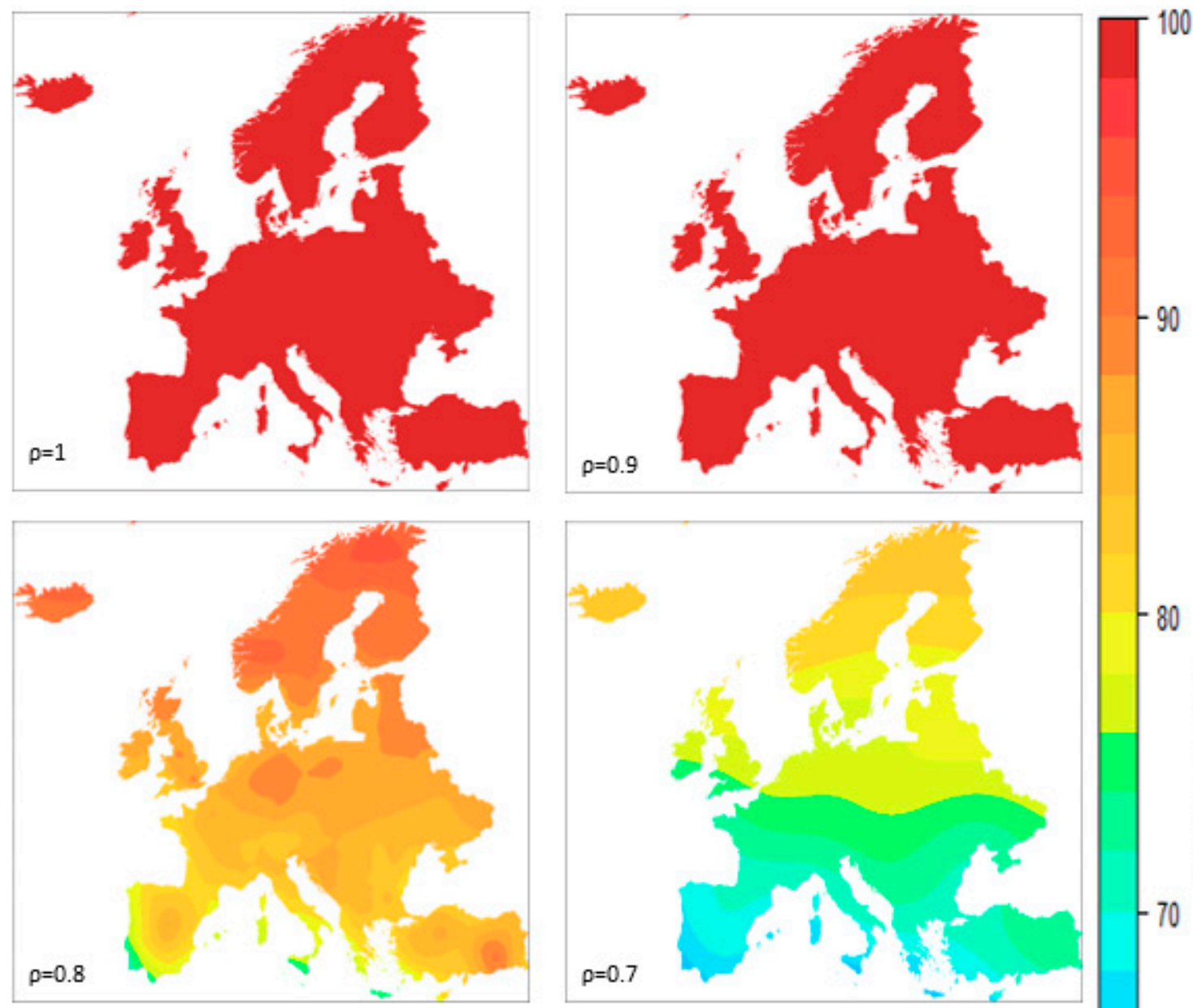

$-80$
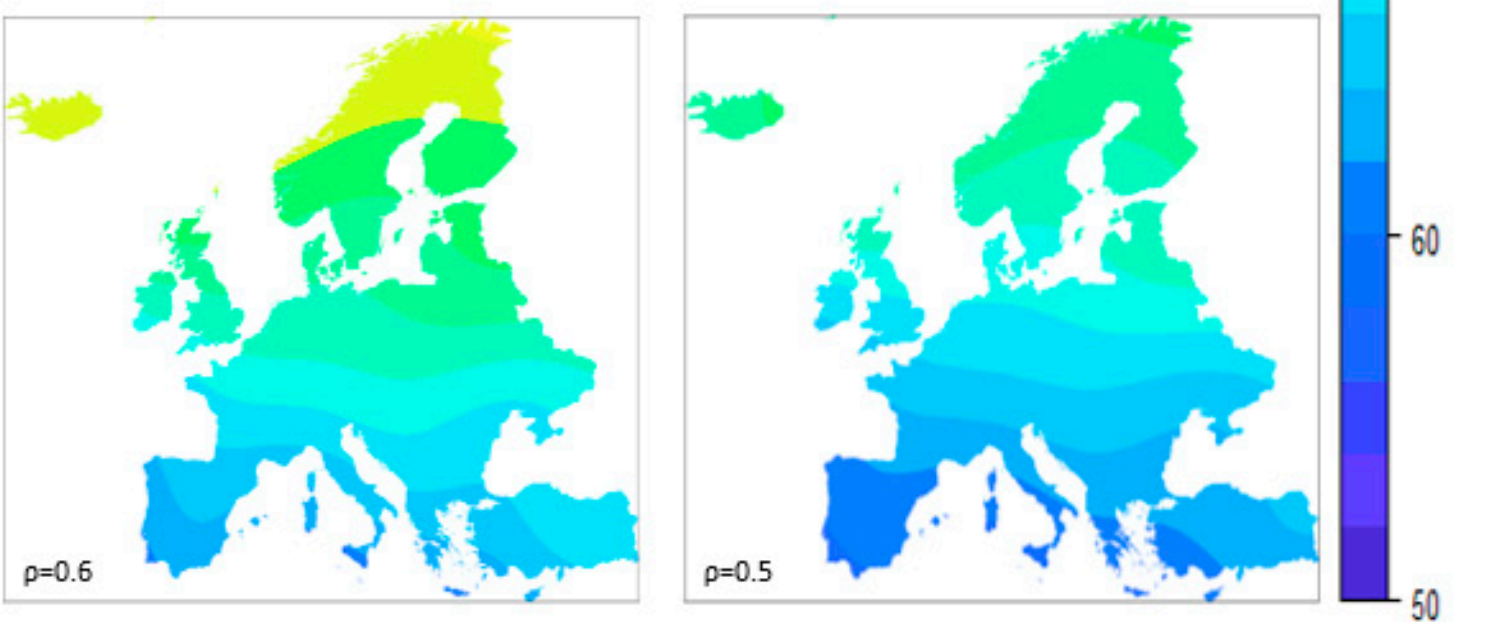

Figure 6. Map of RC activity (\%) for six values of solar radiation reflectivity. 


\subsubsection{Annual Energy Potential}

The maps in Figure 7 show the annual RC energy potential at each point in Europe. It can be seen, again, that the regions of southern Europe are the areas with the highest energy capacity for radiative cooling. For solar reflectivity values between 0.8 and 0.6 , northern regions present higher energy potential than central regions. In this range, although the power potential in the north was lower than in the center (Figures 4 and 5), the north had more time available to perform RC (Figure 6 and Table 6), resulting in higher values of annual energy available.

The available energy was reduced by lowering solar reflectivity (Table 8). At low reflectivities, maps presented a homogenization pattern. When solar reflectivity is equal to 0.5 it behaves as a nighttime surface (when $\rho=0.5$ it was able to provide, on average, $264.87 \mathrm{kWh} / \mathrm{m}^{2}$.year, while a nighttime surface was able to provide $245.76 \mathrm{kWh} / \mathrm{m}^{2}$.year). The largest differences in the average annual RC energy were observed between $\rho=1$ and $\rho=0.8$. In this range, the difference between average values in Europe was equal to $204.67 \mathrm{kWh} / \mathrm{m}^{2}$.year, and it was equal to $272.58 \mathrm{kWh} / \mathrm{m}^{2}$.year in southern Europe. In the range of $0.8-0.5$, the existing difference in the average was equal to $57.56 \mathrm{kWh} / \mathrm{m}^{2}$.year in Europe. Between $\rho=1$ and $\rho=0.8$, the average annual RC energy reduction for Europe was $38.83 \%$, while between $\rho=0.8$ and $\rho=0.5$ it was $17.85 \%$. Small variations in reflectivity have a greater impact on the energy potential at high reflectivity values than at low ones.

Southern countries were more affected by the reduction of $\rho$ than northern and central countries: differences in the average RC energy available between $\rho=1$ and $\rho=0.5$ were $333.63 \mathrm{kWh} / \mathrm{m}^{2}$.year in southern regions, $259.42 \mathrm{kWh} / \mathrm{m}^{2}$.year in central regions and $217.49 \mathrm{kWh} / \mathrm{m}^{2}$.year in northern regions. The model presented a good performance in the six cases (Table 9).

Table 8. Minimum, average and maximum values for each solar reflectivity. Potential maps of annual $\mathrm{RC}$ energy $\left(\mathrm{kWh} / \mathrm{m}^{2} \cdot\right.$ year$)$.

\begin{tabular}{|c|c|c|c|c|c|c|c|c|}
\hline & \multirow[b]{2}{*}{ latitude Range } & & \multicolumn{6}{|c|}{ Solar Reflectivity } \\
\hline & & & 1 & 0.9 & 0.8 & 0.7 & 0.6 & 0.5 \\
\hline \multirow{3}{*}{ Center } & \multirow{3}{*}{$43.46 \mathrm{~N}-53.55 \mathrm{~N}$} & $\min$ & 406.74 & 312.63 & 254.79 & 228.15 & 220.30 & 213.05 \\
\hline & & avg & 514.16 & 396.23 & 309.89 & 278.54 & 263.55 & 254.74 \\
\hline & & $\max$ & 639.71 & 493.03 & 378.74 & 333.92 & 322.46 & 317.90 \\
\hline \multirow{3}{*}{ North } & \multirow{3}{*}{$53.55 \mathrm{~N}-71.15 \mathrm{~N}$} & $\min$ & 384.08 & 313.42 & 258.55 & 232.97 & 221.06 & 213.08 \\
\hline & & avg & 470.99 & 383.47 & 311.62 & 280.07 & 264.03 & 253.50 \\
\hline & & $\max$ & 506.40 & 422.26 & 346.71 & 309.46 & 291.11 & 278.34 \\
\hline \multirow{3}{*}{ South } & \multirow{3}{*}{$34.60 \mathrm{~N}-43.46 \mathrm{~N}$} & $\min$ & 493.88 & 368.86 & 281.38 & 266.07 & 246.96 & 240.26 \\
\hline & & avg & 633.56 & 475.55 & 360.98 & 323.36 & 306.98 & 299.93 \\
\hline & & $\max$ & 822.66 & 642.35 & 492.60 & 413.61 & 397.85 & 388.09 \\
\hline \multirow{3}{*}{ Europe } & \multirow{3}{*}{$34.60 \mathrm{~N}-71.15 \mathrm{~N}$} & $\min$ & 384.08 & 312.63 & 254.79 & 228.15 & 220.30 & 213.05 \\
\hline & & avg & 527.10 & 410.35 & 322.43 & 289.55 & 273.87 & 264.87 \\
\hline & & $\max$ & 822.66 & 642.35 & 492.60 & 413.61 & 397.85 & 388.09 \\
\hline
\end{tabular}

Table 9. Performance of the model of the potential maps of RC energy for different solar reflectivity values.

\begin{tabular}{ccc}
\hline Reflectivity & $\boldsymbol{R}^{\mathbf{2}}(-)$ & RMSE $\left(\mathbf{k W h} / \mathbf{m}^{\mathbf{2}} \cdot\right.$ year $)$ \\
\hline 1 & 0.91 & 21.58 \\
0.9 & 0.83 & 21.34 \\
0.8 & 0.81 & 16.24 \\
0.7 & 0.74 & 16.04 \\
0.6 & 0.81 & 13.30 \\
0.5 & 0.78 & 13.82 \\
\hline
\end{tabular}



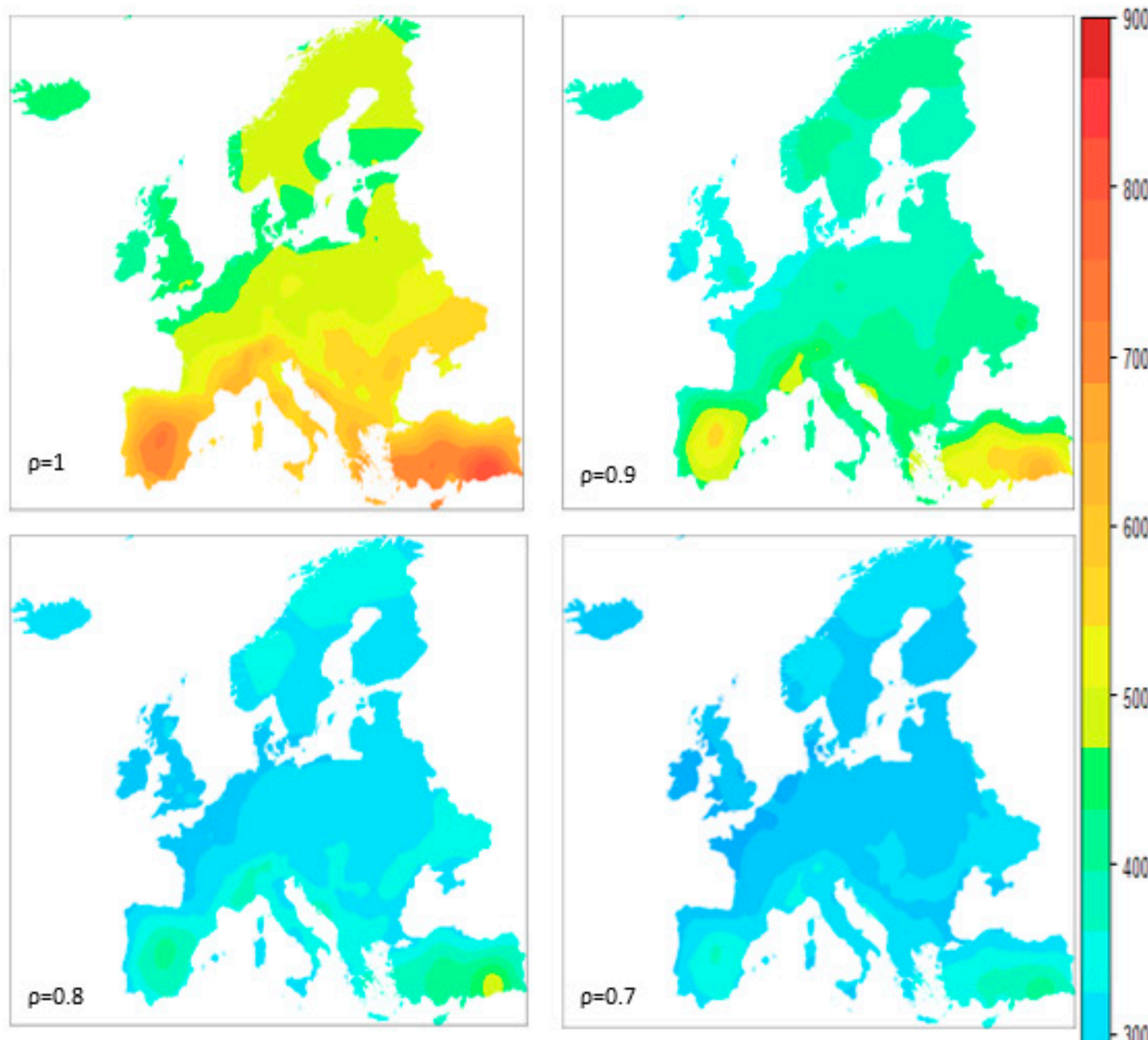

$-600$
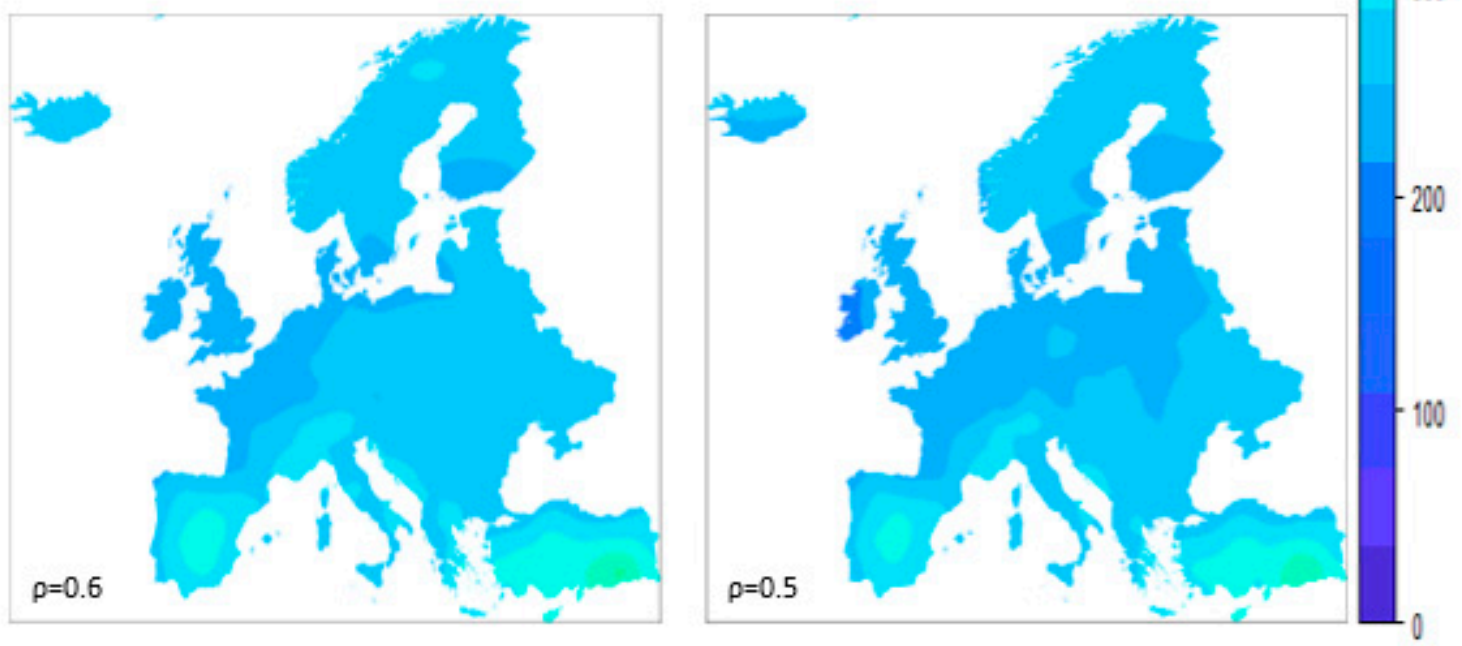

Figure 7. Map of annual RC energy $\left(\mathrm{kWh} / \mathrm{m}^{2}\right.$.year) for six values of solar radiation reflectivity.

\section{Conclusions}

In this article we presented the potential of implementing nighttime and all-day radiative cooling technologies in Europe for different solar reflectivity values of the RC emitting surface. Based on climatological data from weather stations and using Kriging interpolation techniques, maps of annual potential for RC power, RC energy and RC activity were displayed. The following conclusions can be drawn from the study: 
- Kriging is a good methodology to predict radiative cooling values from known climatological data. The models presented high values of $R^{2}$ and low values of RMSE.

- With the implementation of new materials, all-day radiative cooling can be achieved. For solar reflectivity equal to 1 , the shift from nocturnal to all-day radiative cooling can improve the average potential power from 47.30 to $60.17 \mathrm{~W} / \mathrm{m}^{2}$, with peak values of $94.01 \mathrm{~W} / \mathrm{m}^{2}$. The average annual energy increases from 245.76 to $559.47 \mathrm{kWh} / \mathrm{m}^{2}$.year.

- The areas with the greatest potential of implementation are the regions of southern Europe. These regions present high values of power and energy potential.

- Compared to the other regions, the north holds more hours of available radiative cooling.

- The best performance, in all the three regions defined, is achieved when solar reflectivity is equal to one. In order to minimize the solar radiation absorbed by the surface, the reflectivity values in the solar range must be close to 1 .

- For solar reflectivity values below 0.5 , the behavior of the surface can be assimilated to a nighttime radiative cooler.

- Annual energy and RC activity decreases with reflectivity, while average power potential presents higher values in the $0.6-0.5$ range for reflectivity, rather than in the $0.8-0.7$ range. This is a result of calculating the average powers using only the observations where RC is achieved, and not for all the observations; for low solar reflectivity values, $\mathrm{RC}$ observations correspond mainly to nighttime values where high-power values are obtained. On the contrary, for solar reflectivity values between 0.8 and 0.7 , the same nocturnal $\mathrm{RC}$ values are achieved, as well as a higher number of low-power daytime observations, thus reducing the average power. Finally, when the solar reflectivity is equal to 0.9 , diurnal observations present higher powers, thus increasing the average power.

- For low values of solar reflectivity, maps tend to show homogeneous patterns.

- Small variations in solar reflectivity have greater impacts on the potential at higher reflectivity values than lower ones: in the range of $1-0.8$, the reduction of average power potential is $29.19 \%$ and the annual energy is $38.83 \%$.

Author Contributions: Conceptualization, R.V., M.M. and A.C.; methodology, R.V.; software, R.V.; validation, R.V.; formal analysis, R.V.; investigation, R.V.; resources, M.M. and A.C.; data curation, R.V.; writing—original draft preparation, R.V.; writing—review and editing, M.M. and A.C.; visualization, R.V.; supervision, M.M. and A.C.; project administration, M.M. and A.C.; funding acquisition, M.M. and A.C. All authors have read and agreed to the published version of the manuscript.

Funding: This research was funded by the Catalan Government, grant number 2017 SGR 659, and by the Spanish government (Ministerio de Ciencia, Innovación y Universidades), grant number RTI2018-097669-A-I00.

Institutional Review Board Statement: Not applicable.

Informed Consent Statement: Not applicable.

Data Availability Statement: Data set available on request to corresponding authors.

Acknowledgments: The work was partially funded by the Catalan Government under grant agreement (2017 SGR 659), and the Spanish government under grant agreement RTI2018-097669-A-I00 (Ministerio de Ciencia, Innovación y Universidades).

Conflicts of Interest: The authors declare no conflict of interest. The funders had no role in the design of the study; in the collection, analyses, or interpretation of data; in the writing of the manuscript, or in the decision to publish the results.

\section{References}

1. Bahadori, M.N. Passive Cooling Systems in Iranian Architecture. Sci. Am. 1978, 238, 144-155. [CrossRef]

2. Johnson, T.E. Radiation Cooling of Structures with Infrared Transparent Wind Screens. Sol. Energy 1975, 17, 173-178. [CrossRef]

3. Catalanotti, S.; Cuomo, V.; Piro, G.; Ruggi, D.; Silvestrini, V.; Troise, G. The Radiative Cooling of Selective Surfaces. Sol. Energy 1975, 17, 83-89. [CrossRef] 
4. Vall, S.; Johannes, K.; David, D.; Castell, A. A New Flat-Plate Radiative Cooling and Solar Collector Numerical Model: Evaluation and Metamodeling. Energy 2020, 202, 117750. [CrossRef]

5. Sodha, M.S.; Singh, U.; Tiwari, G.N. A Thermal Model of a Roof Pond System with Moveable Insulation for Heating a Building. Build. Environ. 1982, 17, 135-144. [CrossRef]

6. Raman, A.P.; Anoma, M.A.; Zhu, L.; Rephaeli, E.; Fan, S. Passive Radiative Cooling below Ambient Air Temperature under Direct Sunlight. Nature 2014, 515, 540-544. [CrossRef]

7. Cunha, N.F.; AL-Rjoub, A.; Rebouta, L.; Vieira, L.G.; Lanceros-Mendez, S. Multilayer Passive Radiative Selective Cooling Coating Based on $\mathrm{Al} / \mathrm{SiO} 2 / \mathrm{SiNx} / \mathrm{SiO} 2 / \mathrm{TiO} 2 / \mathrm{SiO} 2$ Prepared by Dc Magnetron Sputtering. Thin Solid Film. 2020, 694, 137736. [CrossRef]

8. Kecebas, M.A.; Menguc, M.P.; Kosar, A.; Sendur, K. Passive Radiative Cooling Design with Broadband Optical Thin-Film Filters. J. Quant. Spectrosc. Radiat. Transf. 2017, 198, 179-186. [CrossRef]

9. Mandal, J.; Fu, Y.; Overvig, A.C.; Jia, M.; Sun, K.; Shi, N.N.; Zhou, H.; Xiao, X.; Yu, N.; Yang, Y. Hierarchically Porous Polymer Coatings for Highly Efficient Passive Daytime Radiative Cooling. Science 2018, 362, 315-319. [CrossRef] [PubMed]

10. Peng, L.; Liu, D.; Cheng, H. Design and Fabrication of the Ultrathin Metallic Film Based Infrared Selective Radiator. Sol. Energy Mater. Sol. Cells 2019, 193, 7-12. [CrossRef]

11. Zhang, J.; Zhou, Z.; Quan, J.; Zhang, D.; Sui, J.; Yu, J.; Liu, J. A Flexible Film to Block Solar Radiation for Daytime Radiative Cooling. Sol. Energy Mater. Sol. Cells 2021, 225, 111029. [CrossRef]

12. Bao, H.; Yan, C.; Wang, B.; Fang, X.; Zhao, C.Y.; Ruan, X. Double-Layer Nanoparticle-Based Coatings for Efficient Terrestrial Radiative Cooling. Sol. Energy Mater. Sol. Cells 2017, 168, 78-84. [CrossRef]

13. Hossain, M.M.; Jia, B.; Gu, M. A Metamaterial Emitter for Highly Efficient Radiative Cooling. Adv. Opt. Mater. 2015, 3, 1047-1051. [CrossRef]

14. Zhai, Y.; Ma, Y.; David, S.N.; Zhao, D.; Lou, R.; Tan, G.; Yang, R.; Yin, X. Scalable-Manufactured Randomized Glass-Polymer Hybrid Metamaterial for Daytime Radiative Cooling. Science 2017, 355, 1062-1066. [CrossRef] [PubMed]

15. Cho, J.-W.; Lee, T.-I.; Kim, D.-S.; Park, K.-H.; Kim, Y.-S.; Kim, S.-K. Visible to Near-Infrared Thermal Radiation from Nanostructured Tungsten Anntennas. J. Opt. 2018, 20, 09LT01. [CrossRef]

16. Wu, D.; Liu, C.; Xu, Z.; Liu, Y.; Yu, Z.; Yu, L.; Chen, L.; Li, R.; Ma, R.; Ye, H. The Design of Ultra-Broadband Selective near-Perfect Absorber Based on Photonic Structures to Achieve near-Ideal Daytime Radiative Cooling. Mater. Des. 2018, 139, $104-111$. [CrossRef]

17. Rephaeli, E.; Raman, A.; Fan, S. Ultrabroadband Photonic Structures to Achieve High-Performance Daytime Radiative Cooling. Nano Lett. 2013, 13, 1457-1461. [CrossRef]

18. Zhu, L.; Raman, A.P.; Fan, S. Radiative Cooling of Solar Absorbers Using a Visibly Transparent Photonic Crystal Thermal Blackbody. Proc. Natl. Acad. Sci. USA 2015, 112, 12282-12287. [CrossRef]

19. Gao, M.; Han, X.; Chen, F.; Zhou, W.; Liu, P.; Shan, Y.; Chen, Y.; Li, J.; Zhang, R.; Wang, S.; et al. Approach to Fabricating High-Performance Cooler with near-Ideal Emissive Spectrum for above-Ambient Air Temperature Radiative Cooling. Sol. Energy Mater. Sol. Cells 2019, 200, 110013. [CrossRef]

20. Vall, S.; Castell, A.; Medrano, M. Energy Savings Potential of a Novel Radiative Cooling and Solar Thermal Collection Concept in Buildings for Various World Climates. Energy Technol. 2018, 6, 2200-2209. [CrossRef]

21. Feng, J.; Santamouris, M.; Shah, K.W.; Ranzi, G. Thermal Analysis in Daytime Radiative Cooling. IOP Conf. Ser. Mater. Sci. Eng. 2019, 609, 072064. [CrossRef]

22. Bijarniya, J.P.; Sarkar, J.; Maiti, P. Environmental Effect on the Performance of Passive Daytime Photonic Radiative Cooling and Building Energy-Saving Potential. J. Clean. Prod. 2020, 274, 123119. [CrossRef]

23. Carlosena, L.; Ruiz-Pardo, Á.; Feng, J.; Irulegi, O.; Hernández-Minguillón, R.J.; Santamouris, M. On the Energy Potential of Daytime Radiative Cooling for Urban Heat Island Mitigation. Sol. Energy 2020, 208, 430-444. [CrossRef]

24. Argiriou, A.; Santamouris, M.; Balaras, C.; Jeter, S. Potential of Radiative Cooling in Southern Europe. Int. J. Sol. Energy 1992, 13, 189-203. [CrossRef]

25. Chang, K.; Zhang, Q. Modeling of Downward Longwave Radiation and Radiative Cooling Potential in China. J. Renew. Sustain. Energy 2019, 11, 066501. [CrossRef]

26. Li, M.; Peterson, H.B.; Coimbra, C.F.M. Radiative Cooling Resource Maps for the Contiguous United States. J. Renew. Sustain. Energy 2019, 11, 036501. [CrossRef]

27. Aubinet, M. Longwave Sky Radiation Parametrizations. Sol. Energy 1994, 53, 147-154. [CrossRef]

28. Hengl, T. A Practical Guide to Geostatistical Mapping. 2019, p. 15. Available online: http://spatial-analyst.net/book/system/ files/Hengl_2009_GEOSTATe2c1w.pdf (accessed on 19 August 2021). 